\title{
MONOGRÁFICO
}

LOS CAMPOS DEL SABER EN EL SIGLO XVIII

\author{
Coordinado por \\ Cécile Mary Trojani \\ Universidad Toulouse Jean Jaurès
}



Nota preliminar

\section{Los campos del saber en el siglo XVIII}

Preliminary note The fields of knowledge in the 18th century

Cécile Mary Trojani

Universidad Toulouse Jean Jaurès 

Este monográfico presenta las aportaciones científicas del Congreso Internacional Los campos del saber en el siglo XVIII, celebrado en la Universidad Toulouse-Jean Jaurès (Francia) del 12 al 14 de junio de 2019, y organizado conjuntamente por el Instituto Feijoo de Estudios del Siglo XVIII de la Universidad de Oviedo y el Centre d'Études Ibériques et Ibéro-Américaines (CEIIBAEA7412) de la Universidad Toulouse Jean Jaurès. Dicho encuentro congregó a dieciochistas procedentes de 37 instituciones y 9 países, que compartieron sus trabajos durante tres días organizados en cinco sesiones plenarias y veinte mesas de comunicaciones. Los 27 trabajos ahora publicados, sometidos al habitual proceso de revisión por pares, responden en esencia al espíritu de dicho encuentro; este proponía abordar la constitución de diversos ámbitos del saber en un siglo en el que, precisamente, muchos campos se hallan en pleno proceso de constitución y ordenación, transitando desde la curiosidad intelectual al savoir-faire y a una revolución que con frecuencia no solo es técnica, sino también y sobre todo mental; en el que algunos campos distan de estar plenamente deslindados, mientras otros se alían con esferas insospechadas; en el que con frecuencia el discurso en que los saberes se concretan integra sin complejos elementos estéticos, filosóficos, geográficos, científicos, históricos, políticos, religiosos, económicos, sociales, etc.; y en el que no son pocos, finalmente, los condicionantes que les permiten existir, ya procedan de los propios discursos, formatos, instrumentos, materiales y canales que les dan forma, ya de los contextos sociales, económicos o institucionales en que se generan.

La diversidad de los artículos recogidos en este número monográfico de los Cuadernos de Estudios del Siglo XVIII permite comprobar la riqueza temática y conceptual que alimentó los debates durante el Congreso; al tiempo se puede observar una prometedora efervescencia en torno a unos campos bien definidos, ya sean de índole pragmática o, al contrario, más abstracta.

En el ámbito de las ciencias aplicadas, colocaremos en primer lugar el amplio campo científico de la medicina: si el artículo de Katarzyna Placzek sobre la imagen del cuerpo y de la enfermedad pone las bases de lo que se puede considerar un modo de representación del interés creciente por la salud en la época, el trabajo de Esther Alegre Carvajal lo prolonga con un artículo sobre la erradicación de las epidemias (fiebres tercianas) y de las enfermedades conta- 
giosas, en una perspectiva higienista. Esta vía higienista es la que sigue Alet Valero en su trabajo sobre la hidroterapia y la promoción de aguas minerales, con el ejemplo preciso del balneario de Trillo, donde podemos observar un uso bisagra entre medicina popular multisecular y práctica de moda, algo que anticipa, a finales de la centuria, un fenómeno que será una innovación del siglo XIX, cuando se mezclen preocupación sanitaria y ocio vacacional. El interés por la anatomía, y en particular la del cuerpo femenino, es el eje del trabajo presentado por Sylvie Imparato-Prieur dedicado al arte de partear o sea, la obstetricia que, junto a la cirugía, viene incrementando singularmente los saberes sobre la ciencia médica en aquel siglo, poniendo de relieve tanto la voluntad de medicalizar el embarazo y el parto como la de proteger a las madres y a sus criaturas, en una perspectiva socio-económica.

Ello nos lleva a contemplar algunos de los perfiles de la figura de la mujer en la época ilustrada y la cuestión del género, que aquí se plasman en tres contribuciones: el artículo que firma María Dolores Gimeno Puyol sobre las almanaqueras y la reivindicación de la mujer escritora en plena polémica de los sexos; la contribución que Elena Deanda Camacho dedica a la pornología, definida como subgénero literario de la tradición pornográfica europea; y el análisis de Barbara Luczak sobre la manera de articular la adaptación de los contenidos científicos a un público femenino, a partir de los cursos de botánica para mujeres publicados en el Semanario de Agricultura y Artes dirigido a los Párrocos.

Dicha cabecera periodística también es central en el trabajo que Elisabel Larriba dedica al lugar ocupado por la agronomía (concretamente la «ciencia de la patata») en esta publicación. Es sabido que la prensa, lo mismo que el teatro, ocupan un lugar de predilección en cualquier aproximación a los campos del saber dieciochesco. Al respecto, el artículo de Christian Peytavy tiene el mérito de unir prensa y teatro en la búsqueda frenética del progreso al servicio de la ciencia que el siglo ilustrado hace suya. Y ya específicamente en la categoría teatral cabe situar la contribución de Guadalupe Soria, que profundiza en las relaciones entre las distintas escenas europeas, centrándose en la tratadística actoral.

Esta referencia a las Luces europeas, y en especial a la influencia francesa en un siglo dieciocho español que se tiene por culturalmente afrancesado, conduce a Fernando Calderón Quindós a firmar un artículo dedicado a los $\mathrm{Ca}$ ractères de Botanique de Jean-Jacques Rousseau, donde otra vez comprobamos el interés por las ciencias naturales, mientras Juan Ibeas Altamira y Lydia Vázquez presentan un trabajo sobre el Discurso preliminar de la Enciclopedia de d'Alembert. Los intercambios y los viajes, en especial al extranjero, la circulación de los hombres y de las ideas son, efectivamente, temas relevantes desde el prisma de la preocupación por el progreso y por el descubrimiento de 
nuevos campos del saber o su redefinición. Con el trabajo de Zineb Meghraf nos adentramos en el viaje de espionaje, precursor de los modernos servicios de inteligencia, a través de la figura de Domingo Badía y Leblich, alias Ali Bey el Abassi, y de su viaje por África y Asia. La contribución presentada por Émilie Cadez dibuja al respecto el itinerario europeo de un médico guatemalteco deseoso de construir un telescopio. A esa América española dedican específicamente sus trabajos Patrick Lesbre y Thomas Brignon. El primero nos desvela ciertos manuscritos pictográficos mexicanos utilizando los grabados de la Histoire del jesuita Clavijero, y Brignon explora los campos del saber a través del análisis de dos Vocabularios castellano-guaraníes que reflejan la política linguiística del Paraguay de las misiones jesuíticas.

Otro campo del saber ampliamente abordado en este número monográfico es el de las Bellas Artes, con dos artículos que se refieren concretamente a la Real Academia de Bellas Artes de San Fernando. Así, en un artículo panorámico, Jacques Soubeyroux hace balance de las investigaciones realizadas sobre la Academia de Bellas Artes de Madrid y muestra cómo el movimiento político que llamamos despotismo ilustrado incluía entre sus proyectos la definición de un ámbito de saber propio a las Bellas Artes. Álvaro Molina Martín completa esta perspectiva, analizando con detenimiento el papel desempeñado por las exposiciones temporales en la Real Academia de San Fernando durante la segunda mitad de la centuria, en tanto que nuevo espacio de conocimiento.

Si estas contribuciones refrendan la importancia del fenómeno académico, quizás hubiese sido deseable una contribución más nutrida al variopinto mundo de las Sociedades Económicas de los Amigos del País, tan emblemáticas de las Luces españolas y de su preocupación por el progreso y la felicidad pública. Viene, no obstante, a colmar este vacío el trabajo que dedica Alberto Juan Felani Pintos a la Sociedad Económica Mallorquina de Amigos del País, en el que el autor repasa los proyectos ilustrados y estudia la iniciativa cartográfica de confeccionar un mapa de Mallorca de uno de sus socios.

De este interés por la cartografía y el dibujo se hacen eco otras dos contribuciones: la de Juan Antonio Calatrava Escobar y Ana del Cid Mendoza se refiere a la cartografía urbana como nuevo campo del saber, gracias a la representación de territorios y ciudades a través de la elaboración de planos urbanos, cuya relativa precisión rompe con las viejas aproximaciones. La contribución de Valeria Manfrè expone el proyecto realizado por un ingeniero italiano para la reparación de la cañería del acueducto de Cartagena, a partir de copias de los dibujos y planos realizados por el ingeniero Sebastián Feringán Cortés.

$\mathrm{Al}$ contrastar en detalle este abanico de investigaciones originales, una evidencia se impone: los campos del saber dieciochesco se van construyendo tanto 
en base a la acumulación de conocimientos, cuanto al manejo o dominio de una técnica o savoir-faire; así se percibe en el artículo que Jorge Martínez Montero dedica a la relojería española, describiendo la elaboración de relojes en tierras británicas que luego eran importados hasta la zona del Norte peninsular.

Pero ello no debe llevarnos a soslayar lo que el siglo invierte, humana e intelectualmente, en campos más abstractos. El trabajo de Miguel Ángel Perdomo Batista sobre la filología en la España del siglo XVIII muestra que en dicha época no se puede hablar de esta disciplina como algo uniforme, sino más bien de varias filologías, mezclándose nuevas tendencias con elementos que proceden de la tradición. Y este trabajo encuentra una oportuna prolongación en el de Johan Puigdengolas, dedicado a los inicios de la constitución de los estudios alfonsíes en el siglo XVIII: tal (re)lectura de la época medieval en tiempos de la Ilustración permite calibrar las aportaciones del siglo a la comprensión de épocas anteriores y, a la par, lo que los ilustrados deben a la tradición y a su propia reflexión sobre el pasado. En esta línea de interpretación del pasado a la luz de la razón ilustrada se inscribe el trabajo de María Asunción Sánchez Manzano, que versa sobre el juicio crítico sobre la literatura latina antigua.

Finalmente, Inmaculada Urzainqui y Michel Dubuis vuelven la mirada hacia los orígenes. La primera analiza las reflexiones de B. J. Feijoo sobre la ética profesional, aspecto trasversal a todos los campos constituidos, subrayando su novedad; y Michel Dubuis intenta zanjar la cuestión de si la Ilustración fue o no un movimiento erudito, y propone una reflexión sobre el fenómeno a la luz de los escritos de la época de la llamada pre-Ilustración o Ilustración temprana, sobre cuya importancia nunca se insistirá lo suficiente a la hora de valorar y criticar las empresas ilustradas.

De las referidas a los campos del saber queda aquí alguna, y esperamos que fructífera, constancia. 